\title{
Results of cytopathological studies and mutation analysis in cancer patients from a reference center in western Greece
}

\author{
Fotios Sampsonas \\ Respiratory Department, University of Patras, Greece
}

Correspondence: Fotios Sampsonas, Respiratory Department, University of Patras, Greece, Tel +3069777/ 3684,

Email fsampsonas@gmail.com

Received: February 02, 2018 | Published: May 18, 2018

Copyright@ 2018 Sampsonas. This is an open access article distributed under the terms of the Creative Commons Attribution License, which permits unrestricted use, distribution, and reproduction in any medium, provided the original author and source are credited.

\begin{abstract}
The aim of this study was to present the results of cytopathological studies, performed on samples obtained from patients undergoing bronchoscopy for suspected lung malignancy, in a 12 -month period
\end{abstract}

\section{Methodology}

Between December 2015 and December 2016, 193 patients underwent bronchoscopy for suspected lung malignancy. The cytopathological results were available for 182 patients. Endobronchial biopsies were taken in 61 patients, cytological samples (from bronchial washes and bronchial brushings) were obtained from 79 patients. Transbronchial needle aspiration (TBNA) of lymph nodes of groups 4 and 7 was preformed in 23 patients. Cytology samples were obtained from all 23 patients undergoing TBNA and histology samples were obtained from 20 patients. The EGFR and ALK status were determined for the tumors of 18 and 6 patients, respectively.

\section{Results}

Of the 182 patients, $62(34.1 \%)$ had cancer. Cytology samples were positive in $34.2 \%$ of cases, while endobronchial biopsies and TBNA were positive in $57.4 \%$ and $60.9 \%$ of cases, respectively. All of the tumors examined were negative for the expression of ALK, whereas $2(11.1 \%)$ of those examined expressed EGFR. Non Small Cell Lung Cancer (NSCLC) made up $74.2 \%$ of cases (of which squamous cell carcinoma $27.4 \%$, adenocarcinoma $25.8 \%$ and non-otherwise specified $21 \%$ ) and of SCLC was $25.8 \%$. The results are summarised in Table 1 and Table 2.

Table I Comparison of diagnostic modalities in the diagnosis of lung cancer

\begin{tabular}{lll}
\hline & Total & Positive \\
\hline Bronchoscopies & 182 & $62(34.1 \%)$ \\
Endobronchial biopsy & 61 & $35(57.4 \%)$ \\
Cytology & 79 & $27(34.2 \%)$ \\
TBNA LN4,7 & 23 & $14(60.9 \%)$ \\
EGFR & 18 & $2(11.1 \%)$ \\
ALK & 6 & 0 \\
\hline
\end{tabular}

Table 2 Comparison of diagnostic modalities in the diagnosis of each different type of lung cancer

\begin{tabular}{lllll}
\hline & Total & $\begin{array}{l}\text { Endobronchial } \\
\text { biopsy }\end{array}$ & Cytology & TBNA \\
\hline SCLC & $16(25.8 \%)$ & 6 & 12 & 3 \\
$\begin{array}{l}\text { Squamous cell } \\
\text { carcinoma }\end{array}$ & $17(27.4 \%)$ & 12 & 4 & 0 \\
$\begin{array}{l}\text { Adenocarcinoma } \\
\begin{array}{l}\text { Non otherwise } \\
\text { specified }\end{array}\end{array}$ & $16(25.8 \%)$ & 7 & 8 & 9 \\
\hline
\end{tabular}

\section{Conclusion}

Compared to the international literature ${ }^{1}$ the distribution of histological forms of NSCLC appears to differ, with the incidence of squamous carcinoma being higher in our series $(38.6 \%$, compared to $16.8 \%$ in the literature) while the incidence of adenocarcinoma was lower ( $36.4 \%$, versus $59.7 \%$ in the literature). This difference is probably due to the fact that the present study includes specimens exclusively from bronchoscopies, therefore cases of peripheral adenocarcinomas, in which samples were obtained through CT guided transthoracic biopsies, were not included. EGFR mutation rates are similar to ones described in the literature. ${ }^{2}$

\section{References}

1. Ho C, Tong KM, Ramsden K, Ionescu DN, Laskin J. Histologic classification of non-small-cell lung cancer over time: reducing the rates of not-otherwise-specified. Current oncology. 2015;22(3):e164.

2. Sampsonas F, Ryan D, McPhillips D, P Breen D. Molecular testing and personalized treatment of lung cancer. Current molecular pharmacology. 2014;7(1):22-32. 